\title{
The role of moisture in the nest thermoregulation of social wasps
}

\section{Journal Article}

\section{Author(s):}

Klingner, R.; Richter, K.; Schmolz, E.; Keller, B.

Publication date:

2005-09

Permanent link:

https://doi.org/10.3929/ethz-b-000031107

Rights / license:

In Copyright - Non-Commercial Use Permitted

Originally published in:

Naturwissenschaften 92(9), https://doi.org/10.1007/s00114-005-0012-y 


\begin{abstract}
Paper nests of social wasps are intriguing constructions for both, biologists and engineers. We demonstrate that moisture and latent heat significantly influence the thermal performance of the nest construction. Two colonies of the hornet Vespa crabro were investigated in order to clarify the relation of the temperature and the moisture regime inside the nest. Next to fairly stable nest temperatures the hornets maintain a high relative humidity inside the nest. We found that in consequence a partial vapor-pressure gradient between nest and ambient drives a constant vapor flux through the envelope. The vapor flux is limited by the diffusion resistance of the envelope. The driving force of vapor flux is heat, which is consumed through evaporation inside the nest. The colony has to compensate this loss with metabolic heat production in order to maintain a stable nest temperature. However, humidity fluctuations inside the nest induce circadian adsorption and desorption cycles, which stabilize the nest temperature and thus contribute significantly to temperature homeostasis. Our study demonstrates that both mechanisms influence nest thermoregulation and need to be considered to understand the thermodynamic behavior of nests of wasps and social insects in general.
\end{abstract}

R. Klingner $(\bowtie) \cdot$ K. Richter

Wood Laboratory, EMPA-Swiss Federal Laboratories for

Materials Testing and Research,

Ueberlandstr. 129,

8600 Dübendorf, Switzerland

e-mail: raoul.klingner@empa.ch

Tel.: +41-44-823-4660

Fax: +41-44-823-4007

E. Schmolz

Department of Zoology, Institute of Biology, Freie Universität Berlin,

Königin-Luise-Str.1-3,

14195 Berlin, Germany

B. Keller

Chair of Building Physics, ETH-Swiss Federal Institute of

Technology,

Wolfgang-Pauli-Str. 15,

8093 Zurich, Switzerland

\section{Introduction}

Paper nests of social wasps are intriguing constructions for both, biologists and engineers. The regulation of nest temperature is a complex interaction of constructive and behavioral mechanisms each influencing the thermodynamic behavior of the annually developing nest differently (Hansell 1996; Heinrich 1993). The thermoregulation of nests of Vespula (Gibo et al. 1974a; Gibo et al. 1974b) and Vespa (Himmer 1932; Ishay 1973; Ishay and BarenholzPaniry 1995; Schmolz et al. 2000; Schmolz and Lamprecht 2004) has been researched in detail with the focus on the temperature regime. The influence of moisture was never quantified. Nest ventilation (Riabinin et al. 2004) as well as some unique thermo-electric processes (Ishay and Shmuelson 1996) are mentioned to complement the understanding of the thermal conditions within the nests.

Here, we are able to demonstrate for the first time that moisture and latent heat significantly influence the thermal performance of the nest construction and offer a new perspective in any thermodynamical considerations of social wasp nest thermoregulation in the temperate zone.

\section{Materials and methods}

Two colonies of Vespa crabro (Hymenoptera, Vespinae) were continuously investigated from an early development stage in June until the final leaving of reproductives (queens and drones) in October. The colonies were relocated to the experimental setup outside a laboratory building. The hornets had free access to the environment for foraging. For the presentation of the results we chose a representative week in September with considerable ambient temperature fluctuations and pronounced different modes of thermoregulation.

For the measurement of nest temperature and relative humidity (RH) we used thermocouples, PT100 sensors and capacitive sensors (I-155C/I-155CI, Rotronik). They were placed at different positions within the nest, the envelope, 
and at the envelope surface. The colony in each experimental setup was suspended on a load cell (ELPM-T2M-125N, Entran) for weighing. From the gravimetric development of the whole colony and the final weight of the abandoned nest the share of nest material on total colony weight at the time was approximated. Nest volume and external envelope area were derived from digital pictures taken daily from the nest using image analysis software (Image Access 4.5 ). The micro-topography of the envelope material was not considered using this technique. The water vapor transmission property of the envelope material was determined following EN ISO 12572 (2001). The hygroscopic behavior of complete combs with meconium and silk lining on the cell walls, separated envelope material and a substantial amount of isolated lumps of meconium (dried and hardened larval faeces at the bottom of the cells) was investigated gravimetrically in a climate chamber (PL-JFPW, Tabai Espec Corp.) at $30^{\circ} \mathrm{C}$ and changing $\mathrm{RH}$.

\section{Results and discussion}

\section{Temperature regime}

The vespa species spread in the northern hemisphere face ambient temperatures mostly below the optimal nest temperature. Thus, heating is generally necessary for maintaining a constant nest environment. The obtained difference between nest and ambient temperature drives heat transmission through the nest envelope. To minimize transmission losses the insects aim to increase the thermal resistance of the envelope by adding insulating layers of entrapped air. Based on the temperature difference and the thermal resistance of the envelope the corresponding transmission heat $\operatorname{loss} P_{\text {trans }}$ can be calculated relatively straight forward:

$P_{\text {trans }}=R_{\mathrm{th}}^{-1} \Delta T A_{\mathrm{ext}} \quad[\mathrm{W}]$

where $R_{\mathrm{th}}$ is the thermal resistance of the envelope, $\Delta T$ is the temperature difference between nest and ambient, and $A_{\text {ext }}$ is the external envelope surface area. The thermal resistance $R_{t h}$ of the envelope combines a radiative and a convective component and internal as well as external heat transfer coefficients (Dascalaki et al. 1994). The envelope was considered as a set of layers of entrapped air enclosed by paper-like material. General laws of heat transmission can be applied to approximate $R_{\mathrm{th}}$ relatively precisely.

\section{Moisture regime}

Besides metabolic heat wasp colonies also produce moisture. The individual insects may lose water orally, anally, transcutaneously, and through respiration (Prange 1996). A fraction of the lost water is adsorbed by the surrounding hygroscopic nest material depending on the fluctuation of RH inside the nest. Most of the rest leaves the nest via diffusion through the nest envelope. The buoyancy of warm
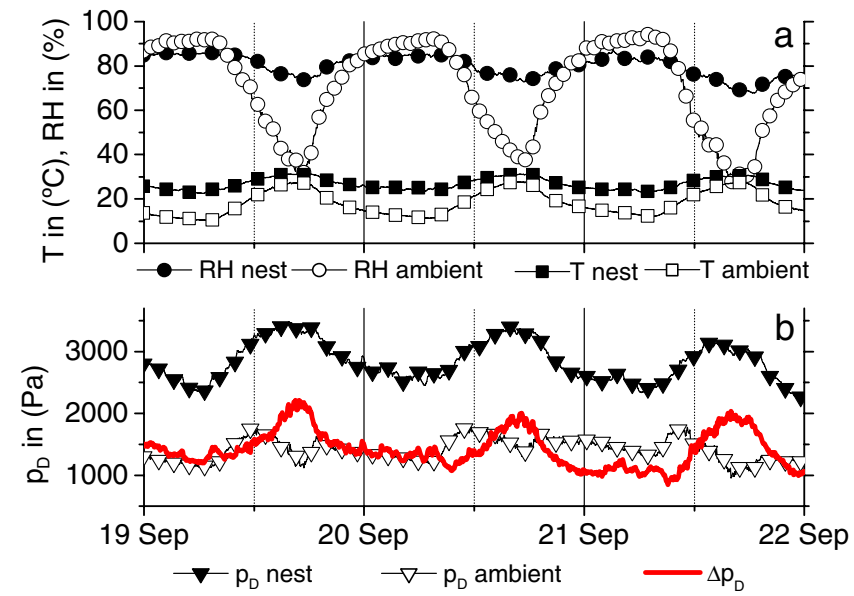

Fig. 1 The difference in temperature $\mathrm{T}$ and relative humidity $\mathrm{RH}$ (a) and consequently partial vapor pressure $p_{\mathrm{D}}$ between nest and ambient (b) results in a partial vapor-pressure gradient $\Delta p_{\mathrm{D}}$ between nest and ambient. Here an exemplary humidity regime over 3 days in September is shown (noon: doted line, midnight: solid line)

and moist air will cause a stable layering of air minimizing heat and vapor transfer through the bottom nest entrance. We considered it negligible; however this is certainly not the case when wasps ventilate the nest trough the entrance. The moisture regime and elevated nest temperatures result in a high RH inside the nest with a markedly reduced circadian fluctuation (Fig. 1a). The difference in temperature and RH causes a vapor-pressure gradient between nest and ambient (Fig. 1b).

Similar to the described heat transfer through the envelope driven by a temperature gradient $\Delta T$, the vapor-pressure gradient $\Delta p_{\mathrm{D}}$ between nest and ambient drives vapor diffusion through the envelope. The amount of diffusion is controlled by the diffusion resistance $R_{\mathrm{d}}$ of the envelope. It can be derived after general laws of vapor transfer (e.g., see Hagentoft 2001) combining the experimentally determined vapor conductivity $\lambda_{D_{-} 1 \text { ayer }}$ of a single envelope layer $(0.011 \pm 0.001 \mathrm{mg} / \mathrm{mhPa})$ with the vapor conductivity $\lambda_{\text {D_air }}$ for air $(0.72 \mathrm{mg} / \mathrm{mhPa})$ :

$R_{\mathrm{D}}=\beta_{\mathrm{A}}^{-1}+\sum_{\mathrm{i}} \frac{d_{\mathrm{i}}}{\lambda_{\mathrm{D}_{-} \mathrm{i}}}+\beta_{\mathrm{I}}^{-1} \quad\left[\mathrm{~m}^{2} \mathrm{hPa} / \mathrm{mg}\right]$

The vapor transfer coefficients $\beta$ are negligible, thus the investigated nest envelopes had a diffusion resistance around $0.2 \mathrm{~m}^{2} \mathrm{hPa} / \mathrm{mg}$ (2). Now the total vapor flow $\dot{m}_{\text {tot }}$ through the envelope can be derived:

$\dot{m}_{\mathrm{tot}}=\frac{\Delta p_{D} A_{\mathrm{ext}}}{R_{d} 1000} \quad[\mathrm{~g} / \mathrm{h}]$

During the night the dew point of the nest air sometimes drops below the measured surface temperature of the outermost envelope layer. This could lead to condensation of part of the vapor flow in outer envelope regions. 


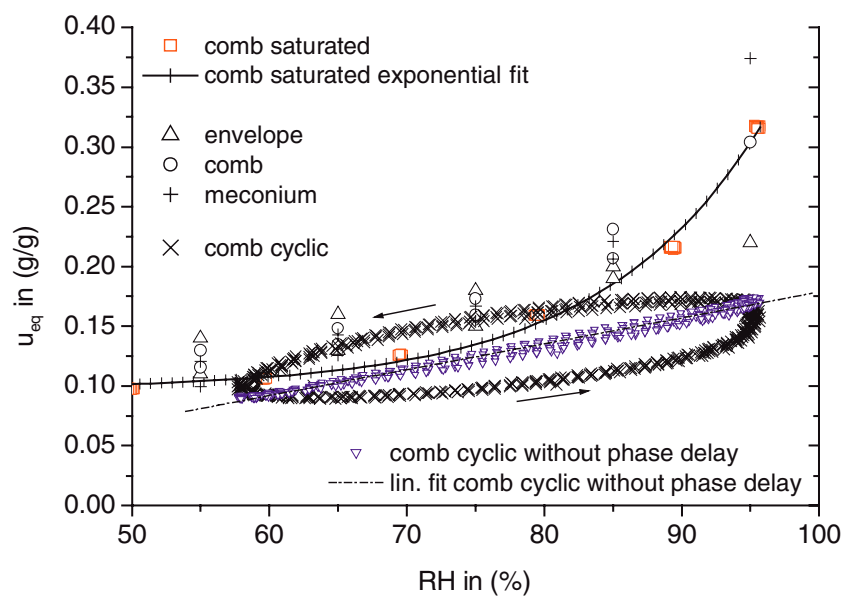

Fig. 2 Sorption behavior of Vespa crabro nest material under cyclic conditions and until saturation. The arrows at the cyclic behavior indicate the direction of sorption. The observed hysteresis is caused by a $3 \mathrm{~h}$ phase delay of the sorption response of the material. The theoretical elimination of the phase delay reveals a linear behavior of the equilibrium moisture content $\left(u_{\mathrm{eq}}\right)$ of comb material under cyclic humidity exposure $\left(y=-0.038+5.4 \times 10^{-5} x, r=0.99\right)$. The phase delay was accounted for in further calculations. The exponential regression refers to the hygroscopic behavior of comb material under exposure until saturation: $y=0.1+6.4 \times 10^{-5} e^{x / 11.8}, r^{2}=0.99$. Envelope, comb and meconium vary in behavior above $80 \% \mathrm{RH}$

The derived vapor flow $\dot{m}_{\text {tot }}$ is a combination of the moisture produced by the colony $\left(\dot{m}_{\text {colony }}\right)$ and mass flows in and out of the hygroscopic nest material via sorption and desorption ( $\left.\dot{m}_{\text {sorption }}\right)$. The sorption flow can be approximated from the sorption isotherm, the amount of hygroscopic nest material and the fluctuation of RH inside the nest. The sorption isotherm of the comb material was determined under cyclic conditions resembling the circadian humidity fluctuations measured in the investigated nests. Moreover comb, envelope and meconium were investigated separately until saturation (Fig. 2). Figure 2 describes the steady state moisture content $u_{\mathrm{eq}}$ of the material plotted as a function of the RH. The cyclic investigation resembling the circadian humidity fluctuation in the real nest shows an hysteresis effect which is mainly caused by a $3 \mathrm{~h}$ phase delay of the sorption response. The investigation of separate nest components until saturation reveals that at a $\mathrm{RH}$ above $80 \%$ the envelope material absorbed significantly less moisture than comb material and meconium itself (Fig. 2).

The rate of sorption $\dot{m}_{\text {sorp }}$ can be calculated from the amount of nest material $m_{\text {nest }}$ available for sorption and the sorptive behavior of the comb material:

$\dot{m}_{\text {sorp }}=m_{\text {nest }} \sigma \frac{d R H}{d t} \quad[\mathrm{~m} / \mathrm{g}]$

where $\sigma$ is the slope of the linear fit of the sorption behavior of comb material under cyclic exposure (Fig. 2).

Now the moisture production of the colony can be approximated from total mass flow through the envelope and the sorption rate of the nest material $\left(\dot{m}_{\text {colony }}=\right.$ $\left.\dot{m}_{\text {tot }}-\dot{m}_{\text {sorp }}\right)$.

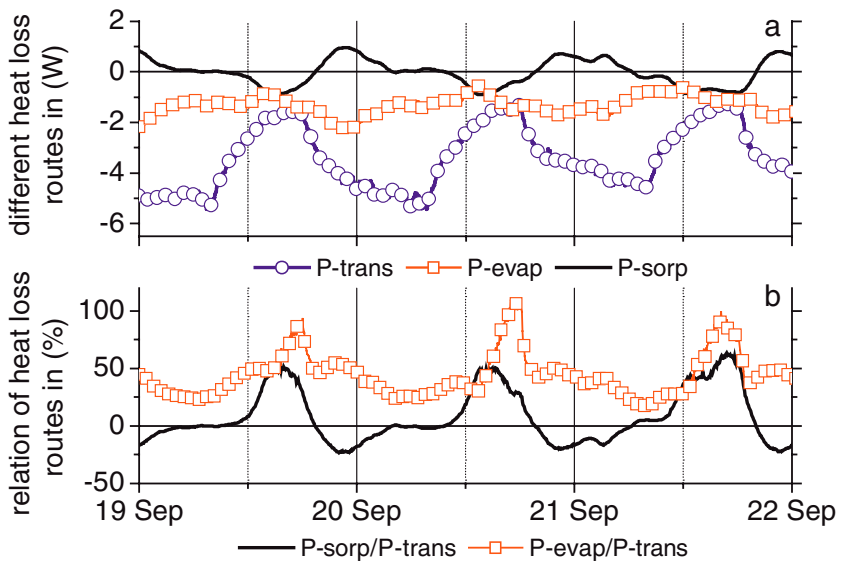

Fig. 3 a Quantification of the different routes of heat loss (transmission loss $P_{\text {trans }}$, evaporative loss $P_{\text {evap }}$ and sorptive heat loss or gain $P_{\text {sorp }}$ ) during exemplary 3 days in September (noon: doted line, midnight: solid line). b Relative importance of moisture-related loss $\left(P_{\text {sorp }}, P_{\text {evap }}\right)$ compared to transmission loss $\left(P_{\text {trans }}\right)$

The sorption processes result in heat of condensation and evaporation. Above $60 \% \mathrm{RH}$ water vapor is bound to porous substrates such as the nest material by capillary condensation and behaves like free water. Thus the heat of evaporation of sorption processes at nest temperature $r_{\mathrm{nt}}$ was approximated to be $2.4 \mathrm{~kJ} / \mathrm{g}$. This also applies to the heat of evaporation of the water lost by the insect. Water lost transcutaneously or through respiration evaporates inside or on the surface of the insect. This lowers the body temperature of the insect and thus reduces heat emission to the nest. Water lost orally or anally evaporates inside the nest and directly lowers the nest temperature. The contribution of each route to overall water loss is still mostly conjecture (Chown 2002). However the mechanisms can be energetically combined to evaporative water loss inside the nest

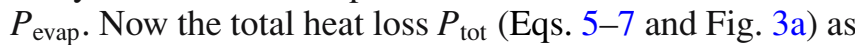
well as the relation between moisture-related mechanisms and transmission heat loss $\left(P_{\text {sorp }} / P_{\text {trans }}, P_{\text {evap }} / P_{\text {trans }}\right.$, Fig. 3b $)$ can be quantified:

$$
\begin{aligned}
& P_{\text {tot }}=P_{\text {trans }}+P_{\text {sorp }}+P_{\text {evap }} \quad[\mathrm{W}] \\
& P_{\text {sorp }}=\dot{m}_{\text {sorp }} r_{n t} \quad[\mathrm{~W}] \\
& P_{\text {evap }}=\dot{m}_{\text {colony }} r_{n t} \quad[\mathrm{~W}]
\end{aligned}
$$

Figure 3a directly compares transmission loss rates with the evaporative loss rate and the rate of sorption of the investigated nest during exemplary days in September. A circadian adsorption and desorption cycle becomes apparent. It has a buffering effect on the nest environment as it runs contrary to the ambient temperature fluctuation.

The evaporative loss slightly decreases during the day when many of the workers have left the nest for foraging. The transmission loss rate is dominant during the night, but in the afternoon moisture driven loss is equally important. Figure $3 b$ shows the relation of evaporative loss and sorption loss/gain to transmission loss. Evaporative loss 
equals transmission loss during the afternoon and varies between 25 and $50 \%$ of it during the rest of the day. Loss by desorption of moisture from the nest material is about half the size of transmission losses during certain times of the day, adsorption gains at night compensate up to $20 \%$ of the transmission losses during the night. However, this only happens late in the colony's development when a considerable amount of hygroscopic nest material is accumulated.

\section{Conclusion}

The moisture regime plays an important part in the regulation of the nest environment of social wasps, which has not been quantified so far. Especially during the day moisture is responsible for over $50 \%$ of the total heat losses. The water loss of the insects influences the thermal nest environment in two ways, by driving circadian sorption processes and by consuming heat of evaporation inside the nest. As both mechanisms involve latent heat they significantly influence the general thermal environment of the wasp nest. Similar passive and energy efficient mechanisms might also be found in construction of other social wasps or social insects such as termites (Turner 2000). They could also inspire the functional design of man-made low-energy constructions. It seems likely to us that these moisture-related processes are important but so far neglected factors in our knowledge about social insect nest thermoregulation in general.

Further research should focus on the quantitative influence of ventilation on the moisture-related processes and the effect of moisture condensation within the envelope.

Acknowledgement We thank K. Weiss and R. Vonbank for their support in constructing the experimental setup. This work was supported by the Swiss National Science Foundation (SNF, Nr. 205321103547). The experiments performed comply with the current laws of Switzerland.

\section{References}

Chown SL (2002) Respiratory water loss in insects. Comp Biochem Physiol A-Mol Integr Physiol 133:791-804
Dascalaki E, Santamouris M, Balaras CA, Asimakopoulos DN (1994) Natural convection heat transfer coefficients from vertical and horizontal surfaces for building applications. Energy Build 20:243-249

Gibo DL, Dew HE, Hajduk AS (1974a) Thermoregulation in Colonies of Vespula arenaria and Vespula maculata (Hymenoptera-Vespidae). 2. Relation between Colony Biomass and Calorie Production. Can Entomol 106:873-879

Gibo DL, Yarascavitch RM, Dew HE (1974b) Thermoregulation in colonies of Vespula arenaria and Vespula maculata (Hymenoptera-Vespidae) under normal conditions and under cold stress. Can Entomol 106:503-507

Hagentoft C-E (2001) Introduction to Building Physics. Studentlitteratur, Lund

Hansell MH (1996) Wasps make nests: Nest make conditions. In: Turillazzi S, West-Eberhard MJ (eds) Natural history and evolution of paper-wasps. Oxford University Press, Oxford, pp 272-289

Heinrich B (1993) The hot-blooded insects: Strategies and mechanisms of thermoregulation. Springer, Berlin

Himmer A (1932) Die Temperaturverhältnisse bei den sozialen Hymenopteren. Biol Rev 7:224-253

Ishay J (1973) Thermoregulation by social wasps: Behavior and pheromones. Transactions New York Academy of Sciences 35:447-462

Ishay JS, Barenholz-Paniry V (1995) Thermoelectric effect in Hornet (Vespa orientalis) silk and thermoregulation in a hornets nest. J Insect Physiol 41:753-759

Ishay JS, Shmuelson M (1996) Thermoelectric properties of the hornet comb: A device for producing, transforming and storing electrical energy for the entire colony. Physiol Chem Phys Med NMR 28:41-54

ISO (2001) EN ISO 12572-Hygrothermal performance of building materials and products-determination of water vapour transmission properties. CEN

Prange HD (1996) Evaporative cooling in insects. J Insect Physiol 42:493-499

Riabinin K, Kozhevnikov M, Ishay JS (2004) Ventilating activity at the hornet nest entrance. J Ethol 22:49-53

Schmolz E, Brüders N, Daum R, Lamprecht I (2000) Thermoanalytical investigations on paper covers of social wasps. Thermochim Acta 361:121-129

Schmolz E, Lamprecht I (2004) Thermal investigations on social insects. In: Lörinczy D (ed) The nature of biological systems as revealed by thermal methods. Kluwer Academic Publishers, Dordrecht, pp 251-283

Turner JS (2000) The extended organism. The physiology of animalbuilt structures. Harvard University Press, Cambridge, MA 